\title{
Semeadura direta de pata-de-vaca (Baubinia ungulata L.) com sementes pré-germinadas para restauração florestal
}

\author{
Rubens Marques RONDON NETO ${ }^{1 *}$, Fabrício Pereira de JESUS ${ }^{1}$, Lucas Alves da SILVA ${ }^{1}$
}

\author{
${ }^{1}$ Universidade do Estado de Mato Grosso, Alta Floresta, MT, Brasil. \\ *E-mail: Rubens.marques@unemat.br
}

(ORCID: 0000-0003-1779-4970; 0000-0001-7806-6542; 0000-0002-3878-4029)

\begin{abstract}
Recebido em 26/04/2021; Aceito em 20/09/2021; Publicado em 11/10/2021.
RESUMO: Este estudo teve o objetivo de avaliar a estratégia de uso de sementes pré-germinadas de pata-devaca (Baubinia ungulata L.) na semeadura direta para restauração florestal. Os tratamentos testados foram: T1= Plantio de mudas em tubetes (Testemunha); T2 = Semeadura direta sem pré-germinação; T3 = Semeadura direta com pré-germinação; T4 = Semeadura direta sem pré-germinação e hidrogel; e T5 = Semeadura direta com pré-germinação e hidrogel. O experimento foi instalado em blocos ao acaso com quatro repetições de 10 mudas ou pontos de sementes semeadas. Aos 100 e 210 dias de instalação do experimento foram feitas as seguintes avaliações: taxa de sobrevivência (Ts); altura total (Ht); diâmetro do colo (Dc); e número de folhas (Nf). A Ts e o crescimento morfológico de B. ungulata regeneradas pelo plantio de mudas não foram superadas pelas estratégias de semeaduras diretas utilizadas, mas a técnica demostrou ser promissora para futuros testes com outras espécies arbustivas e arbóreas de interesse à restauração florestal.
\end{abstract}

Palavras-chave: área degradada; regeneração florestal; regeneração artificial.

\section{Direct seeding of pata-de-vaca (Bauhinia ungulata L.) with pre-germinated seeds for forest restoration}

\begin{abstract}
This study aimed to evaluate the seed use strategy of using pre-germinated seeds of Baubinia ungulata L. in direct sowing for forest restoration. The treatments tested were: T1 = Planting seedlings in tubes (Witness); T2 = Direct sowing without pre-germination; T3 = Direct sowing with pre-germination; T4 = Direct sowing without pre-germination and hydrogel; and T5 = Direct sowing with pre-germination and hydrogel. The experiment was installed in randomized blocks with four replications of 10 seedlings or points of seed sown. At 100 and 210 days after installation of the experiment, the following assessments were made: survival rate (Ts); total height $(\mathrm{Ht})$; diameter (Dc); and number of leaves $(\mathrm{Nf})$. The Ts and the morphological growth of $B$. ungulata regenerated by planting seedlings were not overcome by the direct seeding strategies used, but the technique proved to be promising for future tests with other shrub and tree species of interest to forest restoration.
\end{abstract}

Keywords: degraded area; forest regeneration; artificial regeneration.

\section{INTRODUÇÃO}

A restauração florestal de uma área degradada pode ocorrer naturalmente, denominada de restauração passiva, e/ou através da a interferência humana (restauração florestal ativa). O processo natural ocorre através da regeneração natural de indivíduos oriundos de fontes de propágulos existentes no local ou proximidades, passando pelas fases da sucessão ecológica. Enquanto que no método de restauração florestal ativa o processo sucessional da vegetação ocorre mediante ao plantio de mudas e/ou a semeadura direta de sementes florestais na área degradada.

A técnica de semeadura direta de sementes florestais pode ser utilizada na formação de povoamentos florestais puros e mistos, com fins produtivos ou ambientais. Dependendo da adaptação das espécies florestais a essa técnica de regeneração seu uso tende a ser promissor nas práticas de restauração florestal de áreas degradadas. Tal fato é motivado pelo fato da sua praticidade e agilidade de aplicação em campo, melhorando os rendimentos operacionais de implantação dos componentes arbóreos nos projetos de restauração florestal.
O fornecimento de condições microambientais favoráveis às fases da germinação das sementes em campo depois da semeadura direta é o maior desafio da técnica para sua aplicação às espécies florestais nativas brasileiras. Dessa forma, observa-se a oportunidade de praticar iniciativas de estabelecimento da semeadura direta de espécies florestais nativas utilizando-se sementes pré-germinadas. Segundo Oliveira (2012) a germinação das sementes ocorre quando suas características intrínsecas são adequadas e há condições favoráveis do ambiente (água, oxigênio, luz, temperatura). No entanto, em condições de campo há enormes dificuldades de garantir tais qualidades microambientais para o início da germinação das sementes, assim as outras fases sequências do processo germinativo e o estabelecimento inicial das plantas no povoamento florestal.

O uso de sementes pré-germinadas na semeadura direta poderia ultrapassar as etapas delicadas da germinação que normalmente ocorre em campo. Possivelmente, essa estratégia técnica ajudaria na manutenção das densidades desejadas de indivíduos arbustivos e arbóreos por área no 
ambiente em situação de restauração florestal. A referida técnica de regeneração florestal também tem como perspectiva favorecer especialmente àquelas espécies florestais mais exigentes quanto às condições abióticas ideais aos processos de germinação das sementes em condições de campo. Assim sendo, aumentará a lista de espécies florestais com potencial de regeneração artificial através da semeadura direta, o que pode reduzir os custos com os trabalhos de restauração florestal de áreas degradadas.

Dentre a diversidade de espécies florestais nativas brasileiras que despertam interesse de regenerá-las via semeadura direta para uso na restauração florestal, tem-se a Baubinia ungulata L. Segundo Lorenzi (2020) trata-se de uma espécie florestal nativa pertencente à família Fabaceae. É conhecida popularmente como pata-de-vaca ou mororó, com ocorrência em todo Brasil, exceto na região sul. Quanto ao grupo ecológico é considerada uma planta pioneira e também é seletiva higrófita. Encontra-se presente em florestas semidecíduas e matas ciliares, sendo rústica e ótima para utilização em programas de reflorestamentos.

Desta forma, o presente trabalho teve como objetivo avaliar a estratégia de uso de sementes pré-germinadas de pata-de-vaca (Baubinia ungulata L.) na semeadura direta para restauração florestal.

\section{MATERIAL E MÉTODOS}

O experimento foi instalado na área experimental do viveiro Flora Ação Mudas e Reflorestamento, situada no município de Alta Floresta - extremo norte do Estado de Mato Grosso. O ponto central da área ocupada pelo experimento localiza-se entre as coordenadas geográficas $56^{\circ} 01^{\prime} 88^{\prime \prime}$ W e $09^{\circ} 54^{\prime} 70^{\prime \prime}$ S e altitude de $184 \mathrm{~m}$.

Pela classificação de Köppen o clima da região é do tipo Am, clima tropical úmido ou subúmido, com duas estações bem definidas, verão chuvoso e inverno seco, temperatura média anual em torno de $26^{\circ} \mathrm{C}$ e precipitação média anual na faixa de 2.800 à $3.100 \mathrm{~mm}$ (ALVARES et al., 2014). No local a classe de solo é o Argissolo Vermelho Amarelo. Conforme a Tabela 1 o solo da área experimental apresentava caráter distrófico, com saturação por base (V) menor que 50\%, enquanto que os teores de matéria orgânica, $\mathrm{Ca}, \mathrm{Mg}$ e $\mathrm{K}$ são médios a baixo e a acidez do solo considerada média a elevada.

Tabela 1. Caracterização química do solo da área experimental na profundidade de $0-20 \mathrm{~cm}$.

Table 1. Chemical characterization of the soil in the experimental area at a depth of $0-20 \mathrm{~cm}$.

\begin{tabular}{|c|c|c|c|c|c|c|c|c|c|c|}
\hline $\mathrm{pH}$ & $\mathrm{pH}$ & $\mathrm{P}$ & $\mathrm{Ca}$ & $\mathrm{Mg} \quad \mathrm{AI}$ & $\mathrm{Al}+\mathrm{H}$ & SB & & & & \\
\hline $\mathrm{aC}$ & $\mathrm{H} 2 \mathrm{O}$ & $\mathrm{mg} \mathrm{dm}-{ }^{3}$ & & $\mathrm{cmol} \mathrm{dm}$ & & & & & & \% \\
\hline 42. & 4,9 & 1,5 & $\begin{array}{ll}0,15 & 0,73\end{array}$ & $\begin{array}{lll}0,24 & 0,6\end{array}$ & 4,51 & 1,1 & 5,6 & 2 & & \\
\hline
\end{tabular}

Sendo: $\mathrm{pH}=$ potencial hidrogênico, $\mathrm{P}=$ Fósforo, $\mathrm{K}=$ Potássio, $\mathrm{Ca}=$ Cálcio $\mathrm{Mg}=$ Magnésio, $\mathrm{Al}=$ Alumínio, $\mathrm{Al}+\mathrm{H}=$ Alumínio + Hidrogênio, $\mathrm{SB}=$ Soma de bases, $\mathrm{CTC}=$ Capacidade de troca catiônica, $\mathrm{V}=$ Saturação por bases, $\mathrm{m}=$ Saturação em alumínio.

A fim de suprimir a vegetação de pastagem artificial de capim-braquiarão (Urochloa brizantha (Hochst. ex A. Rich.) R.D. Webster), como também descompactar o solo foram realizadas três gradagens $\mathrm{a} \pm 20 \mathrm{~cm}$ de profundidade. Tal prática de preparo de solo foi realizada 15 dias antes da instalação do experimento.

A pesquisa constituiu no plantio de mudas e diferentes formas de semeadura direta da espécie Baubinia ungulata (pata- de-vaca). As sementes usadas na produção das mudas em tubetes de $50 \mathrm{~cm}^{3}$ e nas técnicas de semeadura direta foram coletadas de três matrizes localizadas em áreas de remanescentes florestais de Alta Floresta/MT. As mudas foram produzidas quatro meses antes da instalação do ensaio em campo.

Os tratamentos testados constituíram no plantio de mudas em tubetes, comparado com os diferentes métodos de semeadura direta, com o detalhe ao uso de sementes prégerminadas e solução de hidrogel nas covas, sendo:

- T1 - Plantio de mudas em tubetes (Testemunha);

- T2 - Semeadura direta sem pré-germinação (SDSPG);

- T3 - Semeadura direta com pré-germinação (SDCPG);

- T4 - Semeadura direta sem pré-germinação e com hidrogel (SDSPGCH);

- T5 - Semeadura direta com pré-germinação e com hidrogel (SDCPGCH).

Em covas de aproximadamente $10 \times 10 \times 10 \mathrm{~cm}$ foram plantadas as mudas feitas em tubetes com médias de $35,3 \mathrm{~cm}$ de altura e 3,70 mm de diâmetro do colo. Para cada cova dos tratamentos testados que tinham como teste a semeadura direta foram colocadas três sementes, distantes a cerca de 2 $\mathrm{cm}$ uma das outras, as quais eram cobertas por uma camada de solo de $\pm 1,5 \mathrm{~cm}$ de profundidade. Tanto para o plantio de mudas como na semeadura de sementes foi estabelecido o espaçamento de $2 \times 1 \mathrm{~m}$ (5.000 plantas ha-1), devido ao curto tempo de avaliação do ensaio. Depois de 75 dias das semeaduras das sementes, foi realizado o desbaste, permanecendo apenas uma planta mais vigorosa de $B$. ungulata por cova (ponto), dessa forma foi possível controlar a densidade e a espacialização dos indivíduos, o que facilita os trabalhos de manutenção do povoamento.

As sementes utilizadas nos tratamentos que tiveram a prégerminação foram lavadas com água e sabão em pó $\left(\mathrm{Omo}^{\circledR}\right)$, assim como o pano de algodão, em seguida enxaguados em água corrente (Figura 1). Todas as sementes eram distribuídas de forma aleatória em única camada no tecido umedecido com água e enroladas em formato de "rocambole". O "rocambole" de sementes era mantido sempre umedecido em ambiente natural e sombreado. O pano e as sementes eram lavados uma vez ao dia com o mesmo sabão em pó e tudo enxaguado em água corrente. A fim de eliminar a presenças de possíveis fungos causadores de apodrecimento das sementes. Essa higienização diária ocorreu até a emissão da radícula, a qual iniciou aos sete dias após a formação do "rocambole". Dessa forma, as sementes com essas características eram consideradas pré-germinadas e prontas para a efetuação da semeadura direta em campo.

Nos tratamentos T4 e T5 que tiveram o uso de higrogel (Hidroterragel $^{\circledR}$ ) a composição da solução foi de $4 \mathrm{~g}$ de hidrogel por litro de água. A dose aplicada por cova foi de 0,5 L, a qual foi colocada no momento da semeadura das sementes e incorporada com o solo. A solução de hidrogel foi preparada cerca de 1 hora e 30 minutos antes da utilização em campo.

O controle da competição com plantas daninhas na área experimental era feito a cada dois meses, através da aplicação de herbicida a base de glifosato, na dose de $300 \mathrm{ml}$ do produto comercial para 20 litros de água. Para evitar possíveis problemas de fitotoxidade com o herbicida as plantas de $B$. ungulata eram protegidas com balde plástico durante a sua aplicação. 

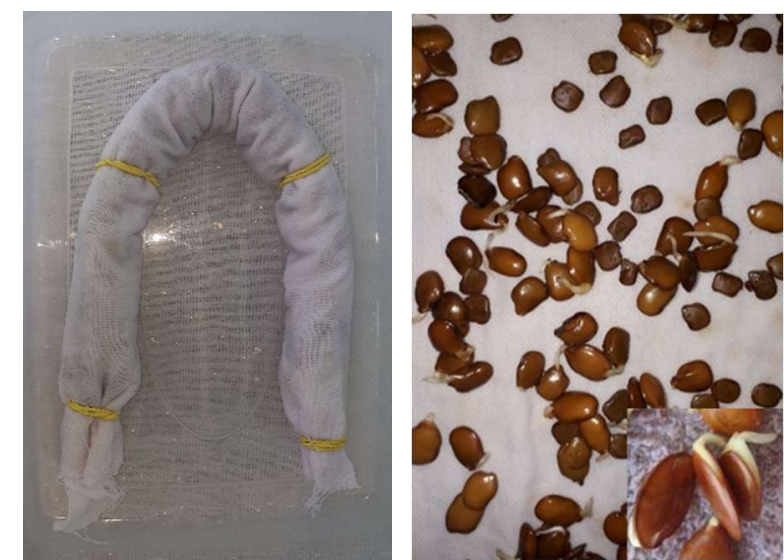

Figura 1. Sementes de Bauhinia ungulata pré-germinadas para posterior semeadura direta em campo.

Figure 1. Pre-germinated seeds of the Baubinia ungulata for direct posterior sowing in the field.

O experimento foi instalado no mês de janeiro do ano de 2018, em pleno período chuvoso na região, no delineamento em blocos ao acaso, com cinco tratamentos testados e quatro repetições de 10 mudas ou pontos de semeadura direta. $\mathrm{O}$ experimento foi avaliado aos 100 e 210 dias após o plantio de mudas e a realização das diferentes técnicas de semeadura direta. Foram mensuradas as taxas de sobrevivência (Ts) e as seguintes variáveis morfológicas das plantas:

- Diâmetro do colo (Dc) - medida da base do tronco, com paquímetro digital ( $\mathrm{mm}$ );

- Altura total $(\mathrm{Ht})$ - distância da base do tronco até o ápice, obtida com trena $(\mathrm{m})$;

- Número de folhas planta $(\mathrm{Nf})$.

Inicialmente, os dados relacionados às Ts e aos crescimentos morfológicos foram analisados quanto a sua normalidade pelo teste de Sahpiro-Wilk. Posteriormente, foi realizada a análise de variância com o emprego do teste $\mathrm{F}$ (P $<0,05)$, e as médias comparadas pelo teste de Tukey $(\mathrm{P}<$ $0,05)$.

\section{RESULTADOS}

$\mathrm{Na}$ Tabela 2 são apresentados os resultados dos testes de comparação de médias para as taxas de sobrevivência (Ts), diâmetro do colo (Dc), altura total $(\mathrm{Ht})$ e número de folhas (Nf), obtidos aos 100 e 210 dias para B. ungulata, regeneradas através de diferentes métodos artificiais. A Figura 2 ilustra indivíduos de B. ungulata regeneradas pelo plantio de mudas e semeadura direta.

Nas duas épocas de avaliações a Ts dos indivíduos de $B$. ungulata não apresentaram diferenças estatísticas significativas entre os tratamentos testados.

Aos 100 e 210 dias de avaliações o Dc das plantas de $B$. ungulata regeneradas pelo plantio de mudas (T1) diferiu estatisticamente dos outros tratamentos que foram feitas as semeaduras diretas, os quais não tiveram diferenças estatísticas entre si.

Nos dois períodos de avaliação do experimento a $\mathrm{Ht}$ de B. ungulata obtida no $\mathrm{T} 1$ diferenciou estatisticamente dos demais tratamentos de semeadura direta. No entanto, T3, T4 e T5 não tiveram diferenças estatísticas entre si, mas diferenciaram dos outros dois tratamentos. Situação idêntica aconteceu na segunda avaliação entre os tratamentos em que foram utilizadas sementes sem pré-germinação (T2 e T4).
Tabela 2. Comparações entre as médias das taxas de sobrevivência e parâmetros de crescimentos de B. ungulata aos 100 e 210 dias de implantação em campo.

Table 2. Comparisons between the mean survival rates and growth parameters of B. ungulata at 100 and 210 days after implantation in the field.

\begin{tabular}{lcccc}
\hline \multicolumn{1}{c}{ Tratamento } & $\begin{array}{c}\text { Ts } \\
(\%)\end{array}$ & $\begin{array}{c}\text { Dc } \\
(\mathrm{mm})\end{array}$ & $\begin{array}{c}\mathrm{Ht} \\
(\mathrm{m})\end{array}$ & $\mathrm{Nf}$ \\
\hline T1 - Testemunha & $100 \mathrm{a}$ & $7,35 \mathrm{a}$ & $0,66 \mathrm{a}$ & $17,83 \mathrm{a}$ \\
T2 - SDSPG & $87,5 \mathrm{a}$ & $3,24 \mathrm{~b}$ & $0,18 \mathrm{c}$ & $9,68 \mathrm{c}$ \\
T3 - SDCPG & $82,5 \mathrm{a}$ & $3,47 \mathrm{~b}$ & $0,22 \mathrm{bc}$ & $9,22 \mathrm{c}$ \\
T4 - SDSPGCH & $77,5 \mathrm{a}$ & $3,65 \mathrm{~b}$ & $0,22 \mathrm{bc}$ & $9,19 \mathrm{c}$ \\
T5 - SDCPGCH & $92,5 \mathrm{a}$ & $4,09 \mathrm{~b}$ & $0,26 \mathrm{bc}$ & $10,57 \mathrm{bc}$ \\
\hline C.V.\% $\%$ & 15,25 & 24,73 & 24,70 \\
\hline \multicolumn{5}{c}{210 dias } \\
\hline T1 - Testemunha & $100 \mathrm{a}$ & $12,06 \mathrm{a}$ & $1,12 \mathrm{a}$ & $27,40 \mathrm{a}$ \\
T2 - SDSPG & $80,0 \mathrm{a}$ & $6,44 \mathrm{~b}$ & $0,33 \mathrm{c}$ & $10,47 \mathrm{~b}$ \\
T3 - SDCPG & $72,5 \mathrm{a}$ & $6,35 \mathrm{~b}$ & $0,52 \mathrm{~b}$ & $10,98 \mathrm{~b}$ \\
T4 - SDSPGCH & $67,5 \mathrm{a}$ & $7,05 \mathrm{~b}$ & $0,48 \mathrm{bc}$ & $11,53 \mathrm{~b}$ \\
T5 - SDCPGCH & $85,0 \mathrm{a}$ & $7,07 \mathrm{~b}$ & $0,61 \mathrm{~b}$ & $8,91 \mathrm{~b}$ \\
\hline C.V.\% $\%$ & 19,26 & 9,04 & 13,38 & 18,00 \\
\hline
\end{tabular}

Sendo: Ts = taxa de sobrevivência, $\mathrm{Dc}=$ diâmetro do colo, $\mathrm{Ht}=$ altura total $\mathrm{e} \mathrm{Nf}=$ número de folhas. Médias seguidas pela mesma letra na coluna não diferem estatisticamente (Tukey, $\mathrm{p}>0,05$ ).
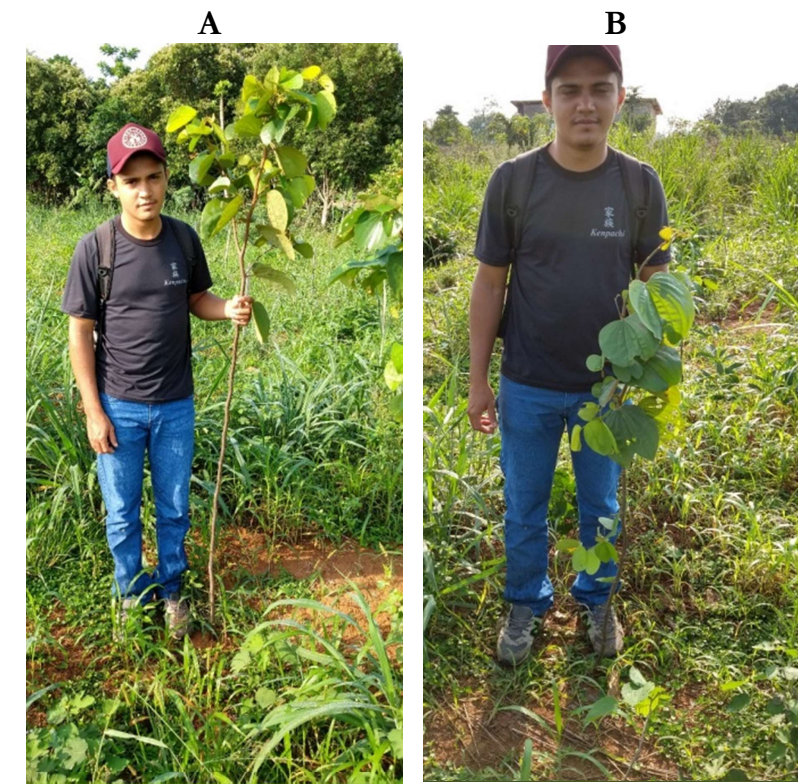

Figura 2. Plantas de B. ungulata regeneradas pelo plantio de mudas (A) e semeadura direta (B) após sete meses de implantação.

Figure 2. Plants of B. ungulata regenerated by planting seedlings (A) and direct sowing (B) after seven months of implantation.

No quesito Nf por planta de B. ungulata, o T1 apresentou diferenças estatísticas com relação aos outros quatro tratamentos de semeadura direta aos 100 e 210 dias da instalação do ensaio em campo. Em ambas as épocas de avaliação todos os métodos de semeadura direta não tiveram diferenças estatísticas entre si, demonstrando assim comportamentos semelhantes em todas as técnicas de semeaduras diretas testadas.

\section{DISCUSSÃO}

Aos 100 e 210 dias de avaliação as respectivas médias da Ts de B. ungulata obtidas no T5 foram cerca de 7,5\% e $15 \%$ inferiores ao tratamento testemunho, que é representado pelo plantio de mudas (T1). A maior Ts obtida no tratamento 
que utiliza sementes pré-germinadas e hidrogel na cova tendeu a garantir o estabelecimento e a densidade desejada de plantas por área. Dependendo da urgência de tempo de fechamento da área degradada pelas copas das árvores os índices de mortalidades obtidos podem ser aceitáveis, ou então, as falhas serem corrigidas por meio de outra semeadura direta ou plantio de mudas.

Houve uma redução dos valores médios de Ts ao longo do tempo em todos os tratamentos feitos por semeadura direta. O motivo de tal fato se deve a maior sensibilidade das plantas jovens em processo de estabelecimento no local às ações dos ataques de insetos e a competição com plantas daninhas. Os indivíduos de B. ungulata ainda com pequeno porte facilmente eram suprimidas pela vegetação competidora ao seu redor e atacadas por insetos desfolhadores. Conforme Waiboonya; Elliott (2020) as mudas florestais pequenas que emergem da semeadura direta apresentam maior vulnerabilidade à competição de ervas daninhas, pragas e doenças e mudanças repentinas das condições ambientais. Assim sendo, a eficiência da semeadura direta deve ser aumentada, para que se torne uma alternativa viável ao plantio convencional de árvores em larga escala.

$\mathrm{Na}$ técnica de semeadura direta testada que teve o uso de hidrogel em solução associado à utilização de sementes prégerminadas (T5) houveram as maiores médias de Ts. O hidrogel favoreceu a existência de condições microambientais favoráveis à continuidade das fases da germinação e o estabelecimento inicial das plantas em campo, principalmente por conta da manutenção da umidade do solo. Fonseca et al. (2017) também detectaram efeitos positivos do hidrogel na redução das taxas de mortalidades de sete espécies arbóreas do Cerrado no período de estação seca, as quais foram regeneradas a via plantio de mudas. Segundo Câmara et al. (2011) a adição de hidrogel ao solo contribui na germinação de sementes, desenvolvimento do sistema radicular, crescimento e desenvolvimento das plantas, redução das perdas de água de irrigação por percolação e melhoria na aeração e drenagem do solo, além de redução das perdas de nutrientes por lixiviação.

$\mathrm{Na}$ segunda época de avaliação do ensaio as variações médias de crescimentos em Dc, Ht e Nf entre os tratamentos que tiveram a semeadura direta foram 3,24 e 4,09 mm, 0,33 e $0,61 \mathrm{~cm}$ e 8,9 e 11,5 folhas, respectivamente. Baseando-se nesses dados dos atributos morfológicos e nas Ts, percebese que B. ungulata apresentou boa performance em regenerar por semeadura direta. Sendo assim, as técnicas de semeaduras diretas podem ser consideradas como adequadas para garantir o processo de estabelecimento das plantas em campo. A fim de manter o pleno andamento da fase inicial de estabelecimento das plantas de B. ungulata seria acentuar a efetividade dos tratos culturais relacionados ao controle de pragas e plantas daninhas. Situação oposta foi obtida por Pellizzaro et al. (2017) um ano após a semeadura direta em campo de B. dumosa, conseguindo média de Ts igual a 52,6\% e Ht de 3,1 $\pm 2,5 \mathrm{~cm}$, comprometendo a densidade de indivíduos na área.

De acordo com Souza; Engel (2018) é preciso entender quais as espécies florestais são adaptadas ao uso dos sistemas de semeadura direta, além de identificar os principais fatores que afetam a germinação, estabelecimento e crescimento. Partindo desse referido princípio, constatou-se que todas essas fases da regeneração de espécies florestais foram alcançadas com o uso de sementes pré-germinadas de $B$. ungulata associadas ao hidrogel. Acredita-se que as técnicas de semeaduras diretas testadas podem substituir a prática do plantio de mudas de B. ungulata ou de forma combinada, reduzindo assim os custos de implantação do projeto de restauração florestal.

\section{CONCLUSÕES}

A técnica de semeadura direta de sementes prégerminadas, associada ao hidrogel demostrou promissora para futuros testes com outras espécies arbustivas e arbóreas de interesse à restauração florestal.

\section{REFERÊNCIAS}

ALVARES, C. A.; STAPE, J. L.; SENTELHAS, P. C.; GONÇALVES, J. L. de M.; SPAROVEK, G. Koppen's climate classification map for Brazil. Meteorologische Zeitschrift, Johannesstr, v. 22, n. 6, p. 711-728. 2014. DOI: 10.1127/0941-2948/2013/0507

CÂMARA, G. R.; REIS, E. F.; ARAÚJO, G. L.; CAZOTTI, M. M.; DONATELLI-JÚNIOR, E. J. Avaliação do desenvolvimento do cafeeiro Conilon robusta tropical mediante uso de polímeros hidro-retentores e diferentes turnos de rega. Enciclopédia Biosfera, Goiânia, v. 7, n. 13, p. 135-146, 2011.

FONSECA, L.; ROITMAN, I.; JACOBSON, T. K. B.; BAIOCCHI, T. K.; OGATA, R. S.; SOLARI, R. A. F., RIBEIRO, R. J. C. Viabilidade do hidrogel na recuperação de Cerrado Sensu Stricto com espécies nativas. Floresta e Ambiente, Seropédica, v. 24, p. 1-8, 2017. DOI: http://dx.doi.org/10.1590/2179-8087.022716

LORENZI, H. Árvores brasileiras: manual de identificação e cultivo de plantas arbóreas do Brasil. 8 ed. Nova Odessa: Instituto Plantarum, 2022. v.1. 384p.

OLIVEIRA, O. S. Tecnologia de sementes florestais: espécies nativas. Curitiba: Ed. UFPR, 2012. 404p.

PELLIZZARO, K. F.; CORDEIRO, A. O. O.; ALVES, M.; MOTTA, C. P.; REZENDE, G. M.; SILVA, R. R. P.; RIBEIRO, J. F.; SAMPAIO, A. B.; VIEIRA, D. L. M.; SCHMIDT, I. B. "Cerrado" restoration by direct seeding: field establishment and initial growth of 75 trees, shrubs and grass species. Brazilian Journal of Botany, São Paulo, v. 40, n. 3, p. 681-693, 2017. DOI: http://doi.org/10.1007/s40415-017-0371-6

SOUZA, D. C.; ENGEL, V. L. Direct seeding reduces costs, but it is not promising for restoring tropical seasonal forests. Ecological Engineering, v. 116, p. 35-44, 2018. DOI: https://doi.org/10.1016/j.ecoleng.2018.02.019

WAIBOONYA, P.; ELLIOTT, S. Sowing time and direct seeding success of native tree species for restoring tropical forest ecosystems innorthern Thailand. New Forests, v. 51, p. 81-99, 2020. DOI: https://doi.org/10.1007/s11056-019-09720-1 